\title{
A LOGÍSTICA E A GESTÃO DA CADEIA DE SUPRIMENTOS: um estudo de caso em uma empresa da região do sul de Minas Gerais
}

Caio Cesar Lemes LEITE ${ }^{1}$

Reginaldo da Silva SOUZA²

Sheldon William SILVA ${ }^{3}$

Pedro dos Santos PORTUGAL JUNIOR ${ }^{4}$

Felipe Flausino de OLIVEIRA ${ }^{5}$

\begin{abstract}
${ }^{1}$ Bacharel em Administração com linha de formação em Comércio Exterior pelo Centro Universitário do Sul de Minas UNIS-MG. caiocesar_lemes@yahoo.com.br

${ }^{2}$ Mestre em Administração pela Faculdade Pedro Leopoldo - FPL-MG. reginaldo_vga@ @otmail.com

${ }^{3}$ Mestre em Administração pela Faculdade Pedro Leopoldo - FPL-MG. sheldonwilliamsilva@gmail.com

${ }^{4}$ Doutor em Desenvolvimento Econômico pela Universidade Estadual de Campinas - UNICAMP-SP. pedrorotaract@hotmail.com

${ }^{5}$ Especialista em Docência no Ensino Superior pelo Centro Universitário do Sul de Minas - UNIS-MG. felipe.oliveira@unis.edu.br
\end{abstract}

Recebido em: 06/07/2016 - Aprovado em: 19/03/2017 - Disponibilizado em: 01/07/2017

\begin{abstract}
RESUMO
O presente artigo tem por finalidade demonstrar a importância do gerenciamento da cadeia de suprimento e seus impactos nas organizações. Para a realização deste estudo, foram pesquisados conceitos sobre logística; Supply Chain e cadeia de abastecimento integrada; a necessidade do inter-relacionamento setorial e o papel das reuniões de S\&OP (Sales and Operations Planning ou Planejamento de Vendas e Operações) para análise de viabilidade de projetos e alinhamento dos mesmos. A pesquisa também apresenta um estudo de caso realizado em uma empresa instalada na região do Sul de Minas Gerais. O estudo culminou no entendimento da necessidade de integração da cadeia logística com a tecnologia da informação, a qual auxiliará nos processos de tomada de decisão que envolvem recursos e clientes, proporcionando um modelo de governança mais estratégico e melhor competitividade no mercado.
\end{abstract}

Palavras-chave: Cadeia de suprimento. Tecnologia. Reunião S\&OP. Planejamento. Logística.

\begin{abstract}
This paper aims to demonstrate the importance of supply chain management and its impact on organizations. For this study, they were surveyed concepts of logistics; Supply Chain and integrated supply chain; the need for sector al interrelationship and the role of the meetings of S \& OP (Sales and Operations Planning) for project feasibility analysis and alignment of them. The survey also presents a case study on a company located in the southern region of Minas Gerais. The study culminated in understanding the need for supply chain integration with information technology, which will help in the decision-making processes that involve resources and customers, providing a more strategic governance model and better competitiveness.
\end{abstract}

Keywords: Supply Chain. Technology. Meeting S\&OP. Planning. Logistics

\section{INTRODUÇÃO}

O cenário mercadológico mudou bastante nos últimos anos e continua em constante transformação. A competitividade das empresas brasileiras é caracterizada por diversos fatores, dentre os quais destaca-se: a concorrência entre as empresas do mesmo ramo de atuação; os custos logísticos e de 
estocagem de materiais; a elevada carga tributária; e o excesso de burocracias e a legislação conservadora brasileira em relação às importações e exportações. Todos estes fatores somados ao mau gerenciamento de recursos limitam as ações das empresas e as tornam não competitivas sob a ótica do desenvolvimento e da qualidade de seus produtos e serviços.

Sabendo-se da importância do bom gerenciamento dos recursos materiais, $\mathrm{o}$ artigo tem como objetivo principal analisar como deve ser estruturada a gestão da cadeia de suprimentos a fim de integrar as áreas da empresa com toda a rede, que consiste nos fornecedores, na própria empresa e nos clientes. Destaca-se, também, a importância da necessidade de haver continuamente reuniões de S\&OP (Sales and Operations Planning ou Planejamento de Vendas e Operações), que discutem os processos dos projetos em andamento e na análise de viabilidade para atender outros requeridos pelos clientes. Por último, o trabalho descreve o suporte que boas ferramentas de gestão dão aos gestores no controle diário das tarefas da empresa e nas tomadas de decisões.

Dessa forma, pretende-se responder à seguinte questão: Quais os principais desafios e oportunidades da gestão da cadeia de abastecimento e do planejamento S\&OP?

Por meio de um estudo de caso em uma empresa instalada no Sul de Minas Gerais, foi possível verificar que o planejamento estratégico que alinha as necessidades de estoque com as demandas dos clientes, dá à empresa vantagem competitiva devido à redução do custo de armazenamento e transporte de materiais; possibilita à empresa a redução do preço final de seus produtos, garantindo assim a satisfação dos clientes e aumentando sua participação de mercado e sua competitividade.

Este trabalho está estruturado em cinco capítulos. O primeiro capítulo trata desta introdução, na qual são apresentados o tema e sua contextualização; o problema de pesquisa, objetivos e uma síntese dos resultados encontrados. O segundo capítulo que inicia o referencial teórico, contextualiza a logística a partir de sua evolução, trazendo os conceitos de supplychain e cadeia de abastecimentointegrada, bem como demonstra o papel das reuniões de S\&OP para a gestão da cadeia de suprimentos. O capítulo terceiro - "Metodologia" - descreve os procedimentos metodológicos utilizados para realização da pesquisa, apresentando sua caracterização, o modelo, a unidade de análise e grupo de respondentes, os instrumentos utilizados para a coleta de dados e a estratégia de análise e tratamento dos dados.

Por fim, apresenta-se no capítulo quatro a análise e discussão dos resultados alcançados a partir da interpretação dos dados coletados por meio da entrevista realizada e, no capítulo cinco, a conclusão do trabalho, 
bem como sugestões para pesquisas futuras e suas limitações. As referências bibliográficas que sustentaram o desenvolvimento do estudo completam o trabalho.

\section{REVISÃO BIBLIOGRÁFICA}

Esta seção tem como objetivo apresentar o referencial teórico que sustenta o estudo proposto. Diante dessa proposição, faz-se necessário percorrer a literatura referente ao contexto de logística, bem como sua evolução, ferramentas e sua interface com os modelos de gestão empresariais.

\subsection{A EVOLUÇÃO DA LOGÍSTICA}

A logística surgiu, segundo Reis (2004), a partir das relações humanas, quando no século XVII, a palavra logistique é derivada de uma patente do exército francês, daqual era designada a exercer atividades relativas ao deslocamento, alojamento $\mathrm{e}$ acampamento das tropas em operação. Em virtude dessa razão, a palavra passou a significar "a arte prática de movimentar exércitos".

A difusão da palavra logística se deu durante a Segunda Guerra Mundial, onde as ações militares demandavam uma melhor provisão e administração dos materiais bélicos, dos suprimentos pessoais, das instalações temporárias, inclusive para a garantia da obtenção de prestação de serviços de apoio. Dessa forma, os exércitos que administravam sistematicamente estas ações, garantiam vantagem competitiva em relação aos seus oponentes, e como consequência, conquistavam novos territórios (REIS, 2004).

Embora o motivo do planejamento estratégico de um líder guerrilheiro não tenha como prerrogativa principal a redução de custos, os objetivos são parecidos na visão de uma empresa capitalista. Neste cenário, a guerra se faz por meio de vantagens que seus produtos ou serviços têm em relação aos concorrentes, dos preços competitivos, tendo a finalidade de aumentar e melhorar a sua participação e a sua imagem no mercado, como também firmar alianças.

Moura (2006, p. 55) ressalta que a evolução desta área administrativa se deu a partir de 1901, quando John Crowell escreveu o artigo acadêmico chamado Report of the Industrial Commission on the Distribution of Farm Products (Relatório da Comissão Industrial para Distribuição de Produtos Agrícolas) que tratava dos problemas de custo da distribuição dos produtos primários nos Estados Unidos da América, devido à distância das áreas de cultivo em relação aos centros consumidores. A partir das décadas de 1950 e meados da de 1960, as empresas passaram a dar maior importância à satisfação dos consumidores devido às suas novas atitudes frente ao mercado, buscando entregar seus produtos com a qualidade exigida, com preço competitivo e em um tempo ágil.

Ainda nesta época, as análises de custo total dos processos logísticos passaram a ser 
mais estudados, dando margem à diversificação dos canais de distribuição. Daí adiante, nos anos 1980, o mundo estava se abrindo para o mercado internacional e a competitividade estava começando a pressionar o mercado interno brasileiro, então, como forma de prevenção e adaptação a essas características, e segundo Costa (2010) a logística empresarial se fragmentou em três grandes áreas, a saber: administração de materiais, movimentação de materiais e distribuição física. A seguir, será explorado cada um dos conceitos.

A administração de materiais segundo Francischini e Amaral (2004) auxilia na gestão de produtos escassos; facilita a visualização das necessidades de aquisição das matérias-primas; permite a empresa adotar técnicas de fabricação sustentável como o Just in Time (JIT) e possibilita a redução dos preços dos produtos acabados, devido à política de redução de estoques.

Para Ballou (1993), o termo movimentação de materiais significa:

Transportar pequenas quantidades de bens por distâncias relativamente pequenas, quando comparadas com as distâncias na movimentação de longo curso executadas pelas companhias transportadoras. É atividade executada em depósitos, fábricas e lojas, assim como no transbordo entre modais de transporte (BALLOU, 1993, p. 172).

A distribuição física é a área da logística empresarial que "trata da movimentação, estocagem e processamento de pedidos. É considerada a área mais importante porque absorve cerca de dois terços dos custos logísticos" (BALLOU, 1993, p. 55). Ainda nessa linha, Bertaglia (2009) explica que por estar associada ao movimento de material, a distribuição física alcança funções como a gestão de estoque, a administração dos pedidos, a armazenagem, o transporte, entre outras. Logo, por fazer parte de tantas ações, conclui-se que sua boa administração faz a empresa obter vantagem competitiva, colocando seus produtos ao alcance dos consumidores.

Para tanto, sabendo da sua história, a logística é, portanto, a junção de quatro atividades para uma empresa: a aquisição de materiais, a movimentação, a armazenagem e a entrega dos produtos transformados. Tudo isso sendo feito com o objetivo único de oferecer aos seus clientes produtos ou serviços de alto nível e com maior valor agregado. A Figura 1 apresenta um fluxograma com as etapas demandadas pelo processo logístico clássico.

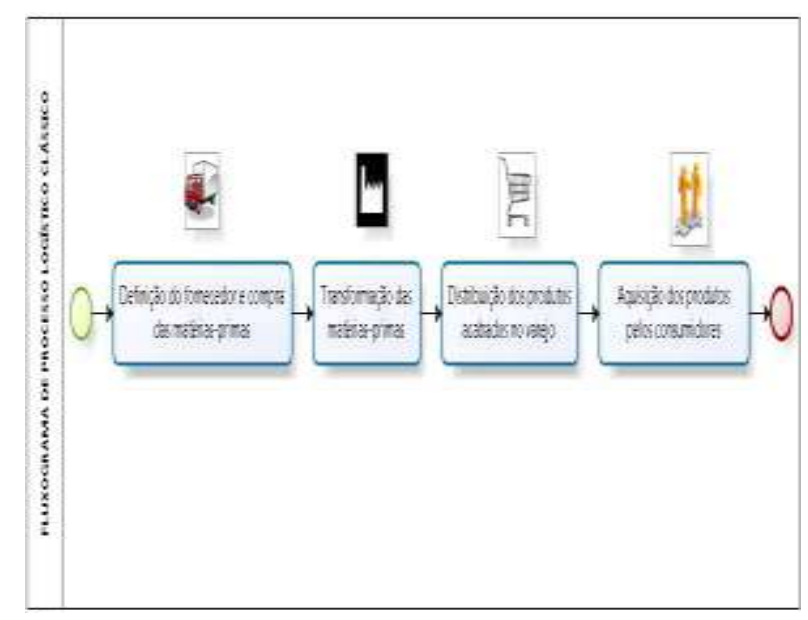

Figura 1: Fluxograma de processo logístico clássico. 
Nesse fluxograma, o início das operações se dá com o contato da empresa com seus fornecedores de matérias-primas, para posteriormente fazer a transformação de tais materiais. Uma vez concluída a produção, é feita a expedição dos produtos para o varejo, e então chegar aos consumidores finais.

\subsection{DEFINIÇÃO DE SUPPLY CHAIN}

No dia a dia, logística e Supply Chain são tratados como sinônimos. Apesar de reconhecida semelhança entre os conceitos, há diferenças entre os termos. De acordo com Bertaglia, Supply Chain significa:

\begin{abstract}
A cadeia de abastecimento corresponde ao conjunto de processos requeridos para obter materiais, agregar-lhes valor de acordo com a concepção dos clientes e consumidores e disponibilizar os produtos para o lugar (onde) e para a data (quando) que os clientes e consumidores os desejarem (BERTAGLIA, 2009, p. 5).
\end{abstract}

Dessa forma, a gestão da cadeia de suprimentos é um processo estratégico. Lida com a previsão da demanda, seleção dos fornecedores, fluxo de materiais, contratos, estuda informações e movimentações financeiras, cria novas instalações como fábricas, armazéns, centros de distribuição; se relaciona com clientes, e trata também de questões mais amplas como a economia, a sociedade, o meio ambiente. Complementando, Novaes (2007, p. 40) aponta que o Supply Chain management "é a integração dos processos industriais e comerciais, partindo do consumidor final e indo até os fornecedores iniciais, gerando produtos, serviços e informações que agreguem valor para o cliente".

Todo este processo de controle feito pela cadeia de abastecimento tem como facilitador, a tecnologia da informação (TI). A TI é para os executivos de logística uma ferramenta de melhoria da produtividade e da competitividade, pois historicamente a comunicação era a parte falha dessa área empresarial (BOWERSOX, 2010). Ainda segundo o autor (2010), a logística integrada e o Supply Chain se beneficiam de cinco tecnologias específicas, a saber: o intercâmbio eletrônico de dados (EDI), computadores pessoais, inteligência artificial e sistemas especialistas, comunicações e código de barras e leitura óptica. Abaixo, o autor define e elenca as funções de cada uma das tecnologias citadas:

O intercâmbio eletrônico de dados (EDI) funciona como um meio de comunicação virtual de forma padronizada, e tem como objetivo aumentar a produtividade interna e externa, auxiliar na eficácia dos relacionamentos entre canais, torna a empresa apta à competitividade internacional e reduzir os custos operacionais, pois reduz a mão-deobra, sua multifuncionalidade exclui a utilização de outras formas de comunicação e diminui o custo burocrático.

A utilização de computadores pessoais passou a ser um equipamento de trabalho de 
todos os departamentos das empresas, pois segundo Bowersox os PCs auxiliam nogerenciamento logístico, reduzindo o custo devido ao acesso rápido às informações, permitindo a descentralização dos processos e deixando a organização mais flexível.

Muitos dos mercados que dependem da logística para poder operar utilizam da inteligência artificial e de sistemas especialistas, que para o autor, é definida como um grupo de tecnologias que tem por finalidade imitar o raciocínio humano. Os sistemas especialistas têm a capacidade de aumentar a produtividade e a qualidade logística, pois tem a finalidade de interpretar dados e extrai-los em conhecimento útil para tomadas de decisões.

$\mathrm{O}$ acesso eficiente às informações sempre foi um problema na área da logística, e a este fato, a comunicação por radiofrequência $(\mathrm{RF})$, por satélite e pelo processo de imagens eletrônicas possibilitou às empresas a obter melhores condições na prestação de serviços aos clientes.

Por último, o código de barras e leitura óptica segundo o autor, funciona como a identidade dos produtos, onde através da leitura óptica é possível identificar as especificidades dos itens, caixas, contêineres ou vagões ferroviários. Esta identificação tem como finalidade indexar o maior número de informações do produto, em uma menor área possível (BOWERSOX, 2010).
O surgimento do Estado Neoliberal no final da década de 1980 e início da de 1990, no Brasil, representou a abertura econômica e o início das atividades nos mercados estrangeiros. A este fato, a internacionalização da economia trouxe para o país a competitividade e forçou as indústrias a planejarem de maneira sistêmica suas atividades (SOUZA, 2011).

A figura 2 ilustra as atividades que a logística integrada interage.

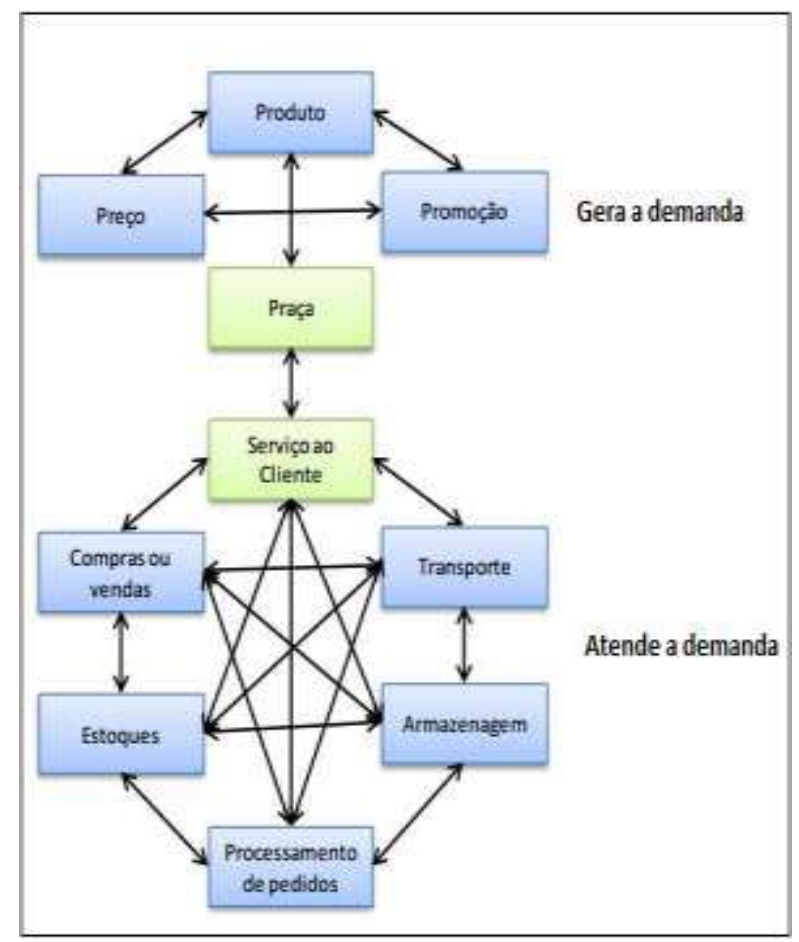

Figura 2: Modelo conceitual de logística integrada.

Os quatro Ps de Porter (Produto, Preço, Praça e Promoção), geradores da demanda, retratados na figura 2 , remete que a logística "deva ser tratada como um sistema, ou seja, um conjunto de componentes interligados, trabalhando de forma coordenada, com o objetivo de atingir um 
objetivo comum" (FLEURY, 2000, p. 35). Logo, os serviços logísticos da empresa trabalharão em conformidade com os fatores geradores da demanda, conforme descrito no modelo acima.

O planejamento é uma importante ferramenta para as atividades empresariais. Planejar a logística significa buscar de forma estratégica, maneiras de condução das ações cujo objetivo seja a obtenção da vantagem competitiva da empresa, e para este fim, as organizações precisam planejar suas competências como forma de vincular dois agentes chaves de todo esse processo: os clientes e os fornecedores (SALIM et al., 2004). Para a implantação e a consolidação do planejamento de integração logística, Bertaglia (2009, p. 29) afirma que a empresa precisa focar em atividades que afetarão seu desempenho no mercado, sendo citado como exemplo: "o desenvolvimento de canais; o planejamento de estoque; produção e distribuição, envolvendo transporte; estimativa de vendas e o planejamento da demanda; o lançamento de produtos e promoções".

O planejamento da integração logística visa vincular a empresa com seus clientes e fornecedores. Para isso, conforme citado no tópico anterior, é necessário haver a integração dos sistemas de informações, para que segundo o autor "as informações sejam filtradas em planos específicos de compra e de produção" (BOWERSOX, 2010, p. 43).
Nessa temática, para planejar a logística integrada de maneira a gerar vantagem competitiva, a empresa precisa seguir dois princípios: ter a convicção de que o comportamento de cooperação de informações entre as partes garantirá a eficiência e a redução de riscos dos processos e procurar identificar e reduzir os trabalhos duplicados e inúteis. Dessa forma, a empresa estará reestruturando seu sistema logístico no contexto do trabalho conjunto, entre as partes internas e externas (BOWERSOX, 2010).

No momento em que a integração logística se expande para fora da empresa, realizando processos que interligam clientes e fornecedores, objetivando beneficiar todas as partes, surge um novo conceito de gestão que representa a evolução da cadeia de suprimentos, o Supply Chain Management (SCM) ou gerenciamento da cadeia de suprimentos.

Sobre o SCM, Ching explica que o:

Supply Chain é todo esforço envolvido nos diferentes processos e atividades empresariais que criam valor na forma de produtos e serviços para o consumidor final. [...] é uma forma integrada de planejar e controlar o fluxo de mercadorias, informações e recursos, desde os fornecedores até o cliente final, procurando administrar as relações na cadeia logística de forma cooperativa e para o benefício de todos os envolvidos (CHING, 2009, p. 67).

Para Christopher (1997, p. 13), “a cadeia de suprimentos representa uma rede de organizações, através de ligações, nos dois sentidos, dos diferentes processos e atividades 
que produzem valor na forma de produtos e serviços que são colocados nas mãos do consumidor final".

A vantagem gerada pelo planejamento logístico possibilita à empresa, a flexibilidade dos preços e as deixa mais competitivas para o mercado globalizado. Porém, ainda segundo Christopher (1999) ter os preços baixos não garante o sucesso da marca, pois devido à vasta oferta de produtos dispostos no mercado, obtém sucesso aqueles que oferecem além de um preço competitivo, uma melhor qualidade.

\subsection{O PAPEL DAS REUNIÕES DE S\&OP}

Na visão de Bertaglia (2009, p. 375), para obter vantagem competitiva em um mercado volátil, as organizações precisam tentar manter a harmonia e o equilíbrio da demanda em relação ao que elas estão ofertando. Neste contexto, planejar as vendas e as operações (S\&OP) permite as organizações a administrarem de maneira mais efetiva o seu Supply Chain, trazendo benefícios globais para a empresa.

Sobre o conceito, o autor apresenta que:

O planejamento integrado de vendas e operações visa harmonizar o processo entre a demanda de mercado e os recursos disponíveis, resolvendo os conflitos funcionais, integrando todas as funções do negócio, com o objetivo de desenvolver um conjunto de números e metas, no qual irão se basear outros planos da empresa e que será a base para medir o desempenho da organização. (BERTAGLIA, 2009, p. 376).
Na visão da American Production and Inventory Society APICS (1998), principal associação profissional voltada para a área de Supply Chain, conceitua S\&OP como sendoum processo que auxilia nas tomadas de decisões, dá à gerência a capacidade de dirigir seus negócios de maneira estratégica e fundamentada, pois reúne as informações das áreas de vendas, marketing, desenvolvimento, fabricação, compras e financeiro em um único plano integrado, podendo vincular planos estratégicos de alto nível com as operações do dia-a-dia.

Neste ponto, o S\&OP atua como uma comunicação integrada dos ambientes empresariais, para chegarem a um resultado final comum. E para garantir o sucesso dessa comunicação, Arozo (2006) lista 11 ações que a empresa precisa implantar, sendo elas: comprometimento da empresa; planejamento de reuniões; definição de responsabilidade; horizonte de planejamento; ferramentas de apoio; grau de agregação; acompanhamento financeiro; documentação do processo; dinâmica de reuniões; monitoramento de desempenho e fluxo de informações.

Uma vez implantados estes processos e instaurado os encontros de planejamento de vendas e de operações, os gerentes e gestores participantes terão definido as intenções das reuniões, objetivando uma discussão sucinta de cada projeto ou plano de ações; terá muito bem delineada as obrigações de cada um, em cada projeto; os integrantes terão relatórios 
financeiros, para auxilia-los em tomadas de decisões mais acertadas e seguras e através do uso de ferramentas de apoio como softwares de MRP e ERP, a quantidade de informações torna estes encontros dinâmicos e garante uma visão holística de toda a cadeia.

De acordo com Bertaglia (2009), os benefícios que a empresa recebe com as reuniões $\mathrm{S} \& O P$ são a redução do nível de estoque, devido ao balanceamento da demanda e das necessidades de abastecimento; o gerenciamento global dos custos; a melhoria do nível de serviço ao cliente; a redução de ordem em atraso; a melhoria da comunicação interdepartamental; a estabilidade do plano de produção; a melhora do nível de decisão da organização, dentre outros.

\section{METODOLOGIA}

Para Gil (2012, p. 19), a pesquisa tem um caráter pragmático, "é um procedimento racional que tem como objetivo proporcionar respostas aos problemas que são propostos". $\mathrm{O}$ artigo do ponto de vista de seus objetivos baseia-se em uma pesquisa descritiva, os meios utilizados foram a pesquisa bibliográfica e um estudo de caso.

Um estudo é caracterizado como descritivo quando o pesquisador levanta dados de forma sistemática e padronizada, pois, tem como objetivo analisar características e costumes como forma de descrever o objeto de estudo e mostrar sua influência no contexto da pesquisa (GIL, 2012).

Ainda de acordo com Gil (2012), a pesquisa bibliográfica é a coleta de informações por meio de materiais já elaborados, usadas para explorar os temas do estudo sem a necessidade de pesquisa de campo. As informações podem ser extraídas de várias fontes, como de livros, enciclopédias e almanaques, publicações periódicas como jornais e revistas, dentre outras.

Como forma de caracterização do tema abordado no presente artigo, houve a necessidade de se realizar um estudo de caso. Segundo Silva (2001), o estudo de caso permite ao autor relatar com maior detalhamento o objeto de estudo.

O estudo de caso foi desenvolvido por meio de uma entrevista em profundidade com um executivo da área de logística de uma empresa instalada na região do Sul de Minas Gerais, para melhor entendimento destas operações, analisando os principais desafios e oportunidades da gestão da cadeia de abastecimento e do planejamento S\&OP. A entrevista foi realizada no mês de maio de 2015, por meio de um roteiro de entrevista enviado e respondido eletronicamente. A escolha da empresa analisada foi baseada no critério de acessibilidade. 


\section{RESULTADOS E DISCUSSÃO}

A entrevista feita para a concretização do estudo abordado foi realizada por meio de uma entrevista com um supervisor da área de planejamento logístico de uma empresa multinacional com uma planta fabril situada no Sul de Minas Gerais e escritórios de gestão em São Paulo.

A organização atua em diversos setores da indústria brasileira, desde eletro portáteis a equipamentos médico-hospitalares. Por comercializar equipamentos tecnológicos, demanda do mercado externo os suprimentos de materiais base para o desenvolvimento de produtos e montagem em suas fábricas no Brasil.

Para um melhor entendimento dos processos da logística integrada e das atividades diárias de uma empresa, a entrevista realizada com o gestor da área buscou explorar os principais desafios e impactos que a implantação desse modo de gerenciamento induz nas organizações.

Neste contexto, com o intuito de apontar os principais desafios e impactos na implantação do gerenciamento da cadeia de suprimentos, o entrevistado evidenciou a necessidade de criação dos Key Performance Indicators (KPIs) ou Indicadores-Chave de Desempenho, para mensurar o nível de desempenho da empresa ou de um processo no qual está inserida. Dessa forma, é possível identificar falhas e direcionar os esforços para a melhoria contínua (PDCA / Plan - Do -
Check - Act - Planejar, Fazer, Checar e Agir) das etapas de suas ações.

Os impactos gerados pela aplicação destas ferramentas no planejamento logístico da empresa são a redução do lead time de produtos, das tarefas e também a redução dos custos operacionais. Para este último, como exemplo da empresa, é possível reduzir os custos operacionais alterando o modal de transporte de um mais caro para outro mais barato, adequando às necessidades dos clientes; entender as prioridades de recebimento e estocagem de materiais, para evitar estoques parados e comprometer o fluxo de caixa da empresa.

No entanto, existem dificuldades inerentes às ações integradas da logística da empresa em que o gestor e sua equipe precisam constantemente equilibrar ou solucionar. De acordo com o gestor entrevistado, uma das maiores dificuldades para o trabalho integrado da logística na empresa é a assertividade do planejamento de demanda de seus produtos, onde se busca obter a previsão de quais e quanto dos produtos o mercado estará demandando da empresa nos próximos seis ou doze meses. Caso o planejamento da demanda não seja feito corretamente, possivelmente a empresa terá problemas como a falta de matériasprimas no momento certo ou uma elevada quantidade de materiais estocados no warehouse (armazém de estoques), comprometendo o fluxo de caixa da empresa. 
Ao abordar o tema sobre como é o acesso às informações de níveis operacionais e estratégicos da organização, o gestor explicou que a empresa trabalhou na sua descentralização, criando fóruns para a discussão entre as áreas interligadas do processo e implantando reuniões operacionais e estratégicas para a divisão das ações entre seus funcionários.

Uma das reuniões feitas é a de S\&OP ou Planejamento de Vendas e Operações, cuja proposta é alinhar as estratégias traçadas com o setor operacional e garantir com que todas as áreas trabalhem em sincronia. Embora esta reunião seja efetiva, segundo o gestor, a empresa precisa primeiramente passar por transformações de comportamento para que o processo possa ser implantado. Em seguida, é necessário que cada setor entenda sua importância e seu papel para que durante as reuniões os gestores de cada área possam fornecer informações corretas para que assim possam ser traçadas metas e estas sejam divididas com o restante da equipe operacional para sua execução.

De acordo com o entrevistado, a empresa utiliza há cinco anos o processo de S\&OP e constantemente a empresa precisa revisar e maturar o processo para que seja mais produtivo. $\mathrm{O}$ gestou destacou que os principais benefícios atribuídos às reuniões de Planejamento de Vendas e Operações vão surgindo de acordo com sua maturidade, podendo destacar: o alinhamento dos funcionários com a estratégia da diretoria da empresa; a visibilidade da necessidade de aumentar o estoque de um produto ou não; criação de campanhas de desconto em cima de produtos "Slow Mover"; possibilita entender se a empresa está enfrentando dificuldade de competitividade em determinada região, entre outros.

Como forma de fomentar a qualidade e assertividade das informações, a empresa utiliza diversas ferramentas eletrônicas para o gerenciamento dos processos, como o SAP, sendo o software base para o controle e criação de relatórios que auxiliam nas tomadas de decisões e sistemas auxiliares em Sharepoint, SalesForce.com, sistema de código de barras no warehouse. O resultado, segundo o entrevistado, é a confiabilidade nas informações, que devido a sua descentralização, estão disponíveis para todos da empresa; a correta separação e utilização de materiais; a disponibilidade de uma base de dados estruturada e a possiblidade de extração de relatórios, utilizados para a criação dos KPIs ou Indicadores-Chave de Desempenho.

\section{CONCLUSÃO}

Ao longo deste trabalho foram apresentados conceitos sobre a logística empresarial e sua evolução no decorrer dos avanços do comércio internacional. Também, o artigo buscou responder de que maneira as empresas podem se tornar mais competitivas 
trabalhando sua logística de maneira integrada, considerando a relação de suas áreas com seus fornecedores e clientes, por meio de reuniões de planejamento de vendas e operações ou S\&OP.

Tendo como base de estudo uma empresa multinacional da área de produtos manufaturados, a pesquisa procurou apontar os desafios e os benefícios de se aplicar o Supply Chain Management (SCM) ou gerenciamento da cadeia de suprimentos na organização e como reuniões de S\&OP ou planejamento de operações e vendas atuam como agente facilitador da logística integrada.

O Supply Chain Management (SCM) foi descrito como uma alternativa para a empresa melhorar sua competitividade no mercado, devido à abertura econômica no final dos anos de 1980 e início dos de 1990. Dessa maneira às indústrias passaram a planejar de forma sistêmica suas atividades como forma de agregar valor aos seus produtos, reduzir custos e prazos em diversos âmbitos organizacionais, integrar processos industriais e comerciais.

A tecnologia da informação é uma ferramenta facilitadora para o gerenciamento da cadeia de suprimentos, pois é considerada uma ferramenta de melhoria da produtividade e da competitividade. Os motivos descritos para ela ser considerada tão essencial são que ela garante agilidade nas trocas de informações; diminui custos burocráticos e operacionais; auxilia no gerenciamento logístico; é capaz de interpretar dados e sintetizá-los em formas de relatórios; podem ser acessadas de qualquer lugar.

As reuniões de $\mathrm{S} \& O P$ têm como objetivo harmonizar o processo entre as demandas e os recursos disponíveis, tornando possível conduzir os negócios de maneira estratégica, fundamentada nas informações das diversas áreas da empresa.

A principal limitação da pesquisa está no próprio método utilizado, o estudo de caso retrata uma realidade específica, que pode ou não ser aplicada em outras organizações e setores econômicos. Dessa forma, sugere-se para novos estudos a realização de uma pesquisa quantitativa que abranja empresas de diversos segmentos de mercado, para analisar a aplicabilidade e utilização do conceito de Supply Chain e das reuniões S\&OP. Como sugestão de continuidade da pesquisa, recomenda-se ainda abordar os temas sobre as estruturas da rede da cadeia de suprimentos; os componentes de gerenciamento da cadeia; os canais de distribuição em relação à logística integrada; a aplicabilidade de reuniões de S\&OP em empresas de médio porte.

\section{REFERENCIAS}

AROZO, R. Sales andOperations Planning: uma maneira simples de obter ganhos com a integração interna. Revista Tecnologística, $n$. 127, junho de 2006.

<Http://professorricardo.tripod.com/Artigo_2 3.pdf $>$. Acesso em: 12 maio. 2015. 
BALLOU, R. H. Logística Empresarial: transportes, administração de materiais e distribuição física. 1.ed. São Paulo: Atlas, 1993.

BERTAGLIA, P. R. Logística e Gerenciamento da Cadeia de Abastecimento. 2.ed. rev. e atual. São Paulo: Saraiva, 2009.

BLACKSTONE, J. H. APICS Dictionary. 9.ed. Virgínia, 1998. Disponível em: <http://www.feg.unesp.br/dpd/scm/claudemir/ part3/Apics\%20Dictionary.pdf> Acesso em: 14 maio. 2015.

BOWERSOX, D. J. Logística Empresarial: o processo de integração da cadeia de suprimentos. 1.ed. São Paulo: Atlas, 2010.

CHING, H. Y. Gestão de Estoques na Cadeia de Logística Integrada: Supply Chain. 4.ed. São Paulo: Atlas, 2010.

CHRISTOPHER, M. A Logística do Marketing: otimizando processos para aproximar fornecedores e clientes. 4.ed. São Paulo: Futura, 1999.

CHRISTOPHER, M. Logística e Gerenciamento da Cadeia de Suprimentos: estratégias para redução de custos e melhoria de serviços. 1.ed. São Paulo: Pioneira, 1997.

COSTA, R. F. Tecnologia da Informação aplicada a logística na Estratégia Empresarial. São Caetano do Sul, v.1, n.3, 2010.

Disponível em:

<http://www.fatecsaocaetano.edu.br/fascitech/ index.php/fascitech/article/view/3

32/31>. Acesso em: 12 maio. 2015.

FRANCISCHINI, P. G.; GURGEL, F. A. Administração de Materiais e do Patrimônio. 1.ed. São Paulo: Pioneira Thomson Learning, 2002.

FLEURY, P. F.; WANKE, P.; FIGUEIREDO, K. F. Logística Empresarial: a perspectiva brasileira. São Paulo: Atlas, 2000.
GIL, A. C. Como Elaborar Projetos de Pesquisa. 4.ed. São Paulo: Atlas, 2012.

MOURA, B. Logística: conceitos e tendências. 1.ed. Lisboa-PT: Inova, 2006. Disponível em:

https://books.google.com.br/books?hl=ptbR\& $\mathrm{lr}=\& \mathrm{id}=\mathrm{uIReFI6gzugC} \&$ oi=fnd\&pg=PA11\&d $\mathrm{q}=$ Moura $+2006+$ John + Crowell\&ots $=$ UqvK_x $\mathrm{PjK} 9 \&$ sig=sKkVK810VnDbVBApc6zqi75aP $\mathrm{a} 4 \# \mathrm{v}=$ onepage $\& \mathrm{q} \& \mathrm{f}=$ false $>$. Acesso em: 12 maio. 2015.

NOVAES, A. G. Logística e Gerenciamento da Cadeia de Distribuição. 3.ed. Rio de Janeiro: Elsevier, 2007.

REIS, P. R. R. Logística Empresarial como Estratégia Competitiva: caso do centro de distribuição da AMBEV. Florianópolis-SC, 2004. Disponível em: < http://tcc.bu.ufsc.br/Contabeis295557.pdf>. Acesso em: 12 maio. 2015.

SALIM, C.; NASAJON, C. V.; SALIM, H.; MARIANO, S. Administração

Empreendedora: teoria e prática usando estudos de casos. 1.ed. Rio de Janeiro: Campus, 2004.

SILVA, E. L., \& MENEZES, E. M. Metodologia da pesquisa e elaboração de dissertação. 4.ed. Florianópolis: Laboratório de Ensino a Distância da UFSC, 2005. Disponível em: $<$ https://projetos.inf.ufsc.br/arquivos/Metodol ogia_de_pesquisa_e_elaboracao_de_teses_e_ dissertacoes_4ed.pdf >. Acesso em: 19 maio. 2015.

SOUZA, A. N. L. Globalização: origem e evolução. Teresina, n. 1, julho de 2011. Disponível em: http://www.faete.edu.br/revista/Artigo\%20An dreia\%20Nadia\%20Globalizacao\%20ABNT. pdf>. Acesso em: 13 maio. 2015. 